\title{
La Cátedra: grupo social complejo
}

The Chair: complex social group
O Presidente: grupo social complexo
Aceptado para su publicación

27 de septiembre de 2014
María Alejandra Gili

Profesora Adjunta. Cátedra de Histología y

Embriología.

Facultad de Odontología. U.N.N.E.

E-mail:magili@odn.unne.edu.ar

Nathalie Enz

Jefe de Trabajos Prácticos. Cátedra Histología y

Embriología.

Facultad de Odontología. U.N.N.E.

E-mail: nenz@odn.unne.edu.ar

Silvia M. Segovia

Auxiliar Docente de Primera Categoría. Cátedra Histología y Embriología.

Facultad de Odontología. U.N.N.E. E-mail: smsegovia@odn.unne.edu.ar

\section{Resumen}

La cátedra no puede ser entendida en forma aislada, sino como una unidad de análisis, pensando en la interdisciplinariedad como un lugar de encuentro que presupone la participación de los actores y la cosificación, en donde se negocian significados acerca de la práctica docente /profesional; no solo está marcada por su propia leyenda, sino que se encuentra profundamente atravesada por las tradiciones de las instituciones y la sociedad a la que pertenece, bajo sus normas, reglamentos o regímenes.

Al hablar de cátedra remite ineludiblemente a ciertos supuestos y conocimientos de sentido común del mundo que vivimos, ligados a la división social del trabajo y la institucionalización del aprendizaje y formación de sujetos determinados socialmente como profesionales y tomando en consideración la función que la misma cumple en la sociedad. La labor docente, en la actualidad, ha sufrido profundos cambios como consecuencia de las transformaciones sociales, políticas, económicas, culturales e históricas, ligada al compromiso con la creación, producción y transmisión del conocimiento en los campos disciplinares de pertenencia.

\section{Palabras claves}

Comunidad. Cátedra. Grupo. 


\section{Abstract}

The chair can not be understood in isolation, but as a unit of analysis, interdisciplinary thinking as a meeting place which presupposes the participation of stakeholders and the objectification, where meanings about teaching / practice are traded; is not only marked by its own legend, but is deeply penetrated by the traditions of institutions and society to which they belong, under its rules, regulations or procedures.

Speaking academic inevitably refers to certain assumptions and common sense knowledge of the world we live in, linked to the social division of labor and the institutionalization of learning and training subjects as professionals and socially determined taking into account the role that it plays in society. The teaching, at present, has undergone profound changes as a result of social, political, economic, cultural and historical, linked to its commitment to the creation, production and transmission of knowledge in the disciplinary fields of belonging.

\section{Keywords}

Community. Cathedra. Group.

\section{Resumo}

O presidente não pode ser entendida de forma isolada, mas como uma unidade de análise, pensamento interdisciplinar como um ponto de encontro que pressupõe a participação de partes interessadas ea objetificação, onde significados sobre o ensino / prática são negociados; não é apenas marcado por sua própria lenda, mas é profundamente penetrada pelas tradições de instituições e da sociedade a que pertencem, sob suas normas, regulamentos ou procedimentos.

Falando acadêmico, inevitavelmente, referese a certas suposições e conhecimento do senso comum do mundo em que vivemos, ligados à divisão social do trabalho e da institucionalização do ensino e formação profissionais e assuntos como socialmente determinada tendo em conta o papel que ela desempenha na sociedade. $O$ ensino, no momento, tem sofrido profundas alterações como resultado de social, político, econômico, cultural e histórica, ligada ao compromisso com a criação, produção e transmissão de conhecimento nas áreas disciplinares de pertença.

\section{Palavras chave}

Comunidade. Presidência. Grupo.

\section{Introducción}

Desde la cátedra se va construyendo el conocimiento científico, el cual se plantea como un proceso histórico de producción y construcción, como producto cultural histórico y materialmente situado'. A partir de lo que ocurre en el interior, de la cátedra, se construye el conocimiento, pero no basta solo con la experiencia, la ciencia da significado, que debe ser contrastado con la experiencia ${ }^{2}$.

El conocimiento trabajado en la universidad es el conocimiento científico, el individuo posee conocimientos previos de todo, aunque sea por analogía. Es el objeto de trabajo, y en torno a él cobran sentido las diferentes tareas ${ }^{3}$.

La cátedra es un acervo de conocimiento, memoria específica producida por las comunidades de práctica que posibilitan una identidad y formación integral. Es el lugar que el curriculum como comunidad de práctica produce, sostiene, conserva y/o cambia, en donde el docente es un portador, multiplicador y transmisor de significados, prácticas y valores $y$, a su vez, integrante legítimo de esa comunidad.

Las comunidades de prácticas realizan un esfuerzo por mantener la integración, pero la realidad nos demuestra que se producen fragmentaciones hacia el interior, generando jerarquías de poder 4 . En la organización de la cátedra se ponen en juego reglas o normas de funcionamiento, roles y funciones, conflictos e interacciones, que dependen de la organización institucional y sus aspectos históricos.

Desde la perspectiva de lo institucional, la cátedra se constituye como una organización visible, compleja, concretada en tiempo y espacio, como medio que permite cumplir lo que la institución establece. Además, es una estructura social con una organización que presupone interacciones humanas, estructuras de jerarquía y poder, en donde las decisiones surgen por acuerdos o sumatorias, que se toman en- 
REVISTA FACULTAD DE ODONTOLOGÍA

ISSN No 1668-7280 - Vol. VIII № 1 - 2015
EDUCACIÓN

La Cátedra: grupo social complejo tre los sujetos involucrados, y como resultado de un proceso colectivo ya que se combina el hacer, hablar, pensar, sentir y pertenecer de diferentes actores ${ }^{5}$.

La sociedad es una producción humana que acontece por la misma acción de los seres humanos. Asimismo, el hombre actúa en un orden social en donde son las reglas las que crean la sociedad. Esto sólo es posible mediante la participación en la práctica comunicativa cotidiana ${ }^{6}$.

Desde la cátedra entendida como un espacio táctico material y simbólico, donde se producen formaciones grupales específicas y singulares relaciones, los grupos constituyen un campo de mediaciones entre individuos y sociedad, entonces, nos planteamos la relación gruposociedad en términos de interacción mutua, en donde lo social se ubica como algo exterior al grupo sobre el cuál recaerá, en mayor o menor medida, su influencia ${ }^{7}$.

Las interacciones entre los integrantes del grupo (cohesión, liderazgo, roles, etc.) se encuentran atravesadas por la institución, el contexto social, momentos históricos determinados, que confluyen en la cuestión grupal. Podemos decir que, existen roles disfuncionales entre los miembros del grupo, desde un intento por satisfacer las necesidades individuales por sobre las grupales. Los roles individuales son indicadores de la existencia de un conflicto, inherente e inevitable a todo grupo, que permanece sin ser resuelto, afectando la eficacia en relación a la tarea y la permanencia de sus miembros ${ }^{8}$.

El grupo no es la suma de las partes sino algo nuevo y distinto que se va dando por la interacción entre sus integrantes, desde la integración estructural del grupo como un todo. Misión imposible cuando no existen expectativas de relación de los miembros entre sí, sumado a actitudes individualistas y rivalidades que se anteponen y que, de algún modo, obstaculizan el funcionamiento limitando la capacidad creativa de sus miembros, anulando el deseo de hacer?.

Es posible generar una dinámica, una vez asumido el conflicto, trabajando para buscar soluciones a los problemas que se van presentando, desarrollando el currículum, poniendo a prueba el conocimiento disponible y aprendiendo de la práctica, para poder mejorarla en un proceso continuo de reconstrucción del conocimiento ${ }^{10}$.
Asimismo, para que los conocimientos adquiridos y las experiencias formadoras puedan ser integradas es necesaria la transformación en uno mismo, es necesario detenerse a pensar y analizar" ", desde la profesión de ser docente, sobre las situaciones a las que se enfrenta a diario, para que realmente se produzca el cambio y la toma de decisiones, que presupone toda práctica docente.

La cátedra pensada como trayecto de formación, es un instrumento que tiene como objetivo permitirnos reflexionar y analizar cada uno de los procesos que se van viviendo y construyendo desde la práctica y la propia experiencia ${ }^{12}$. Constituye un espacio propio y distinto de competencias profesionales, en cuanto a la capacidad (habilidad), aptitud, conocimiento (disciplinar y específico propio de la profesión), responsabilidad y actitud, con que un sujeto es capaz de desempeñar la tarea en un contexto particular y que le permita resolver situaciones complejas ${ }^{13}$.

Como profesionales de la enseñanza se debe asumir a la docencia como una actividad profesional, con todo lo que ello implica, donde se hace necesaria la formación y la integración como un proceso que debe durar toda la vida ${ }^{14}$. Además, como parte integrante de un grupo social, el sujeto no solo es intérprete de sí mismo sino también de los otros, dentro de un contexto de significados que determina cierta forma de participar y relacionarse con el mundo del vivir ${ }^{15}$.

\section{Conclusión}

La significación de un grupo social en la vida de las personas es marcado como momentos y episodios muy cargados, no están planificados, ni anticipados, ni controlados, que promueven el desarrollo de las personas, actitudes hacia el aprendizaje, comprensión de uno mismo, relación con los otros, adquisición de conocimiento y desarrollo de habilidades.

La experiencia y pertinencia de una cátedra ayuda a hacernos personas, produciendo una transformación de cómo vemos y comprendemos el mundo y a nosotros mismos dentro de ese mundo, restaurando la confianza, principios, valores y confirmando la propia filosofía práctica y personal. 
Al mismo tiempo, a través del conocimiento impartido en la universidad podemos comprender desde su función epistémica el "por qué" pasan las cosas, por qué son de una determinada manera y no de otra, para ayudarnos a reestructurar determinadas situaciones, en donde las cosas no han salido del todo bien y fracasen las teorías. Las ideas no surgen del vacío, sino que nacen de un conocimiento específico que en la universidad ha de ser tan extenso como lo es la ciencia misma.

\section{Bibliografia}

I. Woods, M. Experiencias críticas en la enseñanza y el aprendizaje (extracto del capítulo I). España: Paidós. 1997. p. 19.

2. Bachelard, G. La formación del espíritu científico. $19^{\circ}$ ed.. México: Siglo XXI ed. Palabras preliminares; 1993. Cap. I. pp. 15-26.

3. Kuhn, T. S. La estructura de las revoluciones científicas. Buenos Aires: FCE; 1992 Cap. I. Pp. 2I-32.

4. Vasilachis de Gialdino, I. Métodos cualitativos I. Los problemas teóricos-epistemológicos. Buenos Aires: Centro editor de América Latina; 1993. Tesis N5. pp.43-56.

5. Aguayo, C. Las profesiones modernas: dilemas del conocimiento y del poder. Buenos Aires: Editorial Espacio; 2000.

6. Martini, B. A. (2009). La interdisciplinariedad y el currículum. Conferencia en el XV de la Red Universitaria Latinoamericana de Cátedras de Viviendas, realizado en la Unne. http:/arq.unne. edu.ar/jornadasyseminarios/ulcav. pp. 12-20.

7. Fernández, A. M. (1999). El campo grupal: Notas para una genealogía. Buenos Aires: Nueva Visión. Cap. 2. pp. 37-59.

8. Romero, R. R. (1992). Grupo: Objeto y teoría Vol. II. Buenos Aires: Lugar. Cap. I. Pp. II-2. Cap. 2. pp. 25-35. Cap. 4. pp.48-73. Cap. 6. pp. I0I-I30.

9. Board, R. (1997). El psicoanálisis de las organizaciones. Un enfoque psicoanalítico de la conducta en grupos y organizaciones. Buenos Aires: Paidós. Cap. 5. pp. 45-55.

10. Schön, D. (1992). La formación de profesionales reflexivos. Hacia un nuevo diseño de la enseñanza y el aprendizaje en las profesiones. España: Paidós. pp. |7-5I.
II. Zabalza M. y Zabalza Cerdeiriña M. A. (2010). Planificación de la docencia en la universidad. Elaboración de las Guías Docentes de las Materias. Nancea, S. A. de Ediciones. Madrid. España. Cap. 7. pp. |4|-|55.

12. Litwin, E. (1997). Las configuraciones didácticas. Una nueva agenda para la enseñanza superior. Editorial Paidós. Buenos Aires. Cap. 2 y 4.

13. Álvarez de Eulate, C. Y. (2006). Planificar la enseñanza universitaria para el desarrollo de competencias. Educatio Siglo XX, 24. pp. 17-34. Sanjurjo, L. y Rodríguez, X. (2003). Volver a pensar la clase. Rosario: Homo Sapiens. Cap. 2.

14. Zabalza, M. A. (2007). Competencias docentes del profesorado universitario. Calidad y desarrollo profesional. Nancea, S. A. de Ediciones. Madrid. España. Cap. $I$ y 2. 